\title{
An examination of the factorial structure of the unforced-error measure in collegiate women tennis players in Japan: A comparison between players and coaches
}

\author{
Daisuke Hirata, Shuhei Sato, Kiso Murakami (JAP), et al.
}

ITF Coaching and Sport Science Review 2017; 71 (25): 9 - 11

\begin{abstract}
Unforced errors are a significant issue in producing high performance in tennis. Identifying the causes of these errors in important to guide interventions to reduce unforced errors. The purpose of this study was to examine the different causes of unforced errors (UE) of Women's Collegiate tennis players from the perspectives of coaches and players. Specifically, and based on previous research (Hirata, Sato, Murakami, Sato, \& Saijo, in press; Shibahara, Tamaki, Hirata, Sonobe, Morii, \& Saijo, 2015), a measure was developed to collect data on UE. The factor structure was examined using data collected from 283 Collegiate women tennis players and 77 coaches of women tennis players. These participants were divided into High-Skilled (HS) and LowSkilled (LS), where the criteria for such selection was based in the competition level played in different Competitions. In order to access the HS competition, players needed to be winners of the LS competition. Comparing and contrasting both groups are in the basis of the current research study.
\end{abstract}

Key words: Tennis, error, factor analysis,

Received: 12 Dec 2016

Accepted: 07 Feb. 2017

Corresponding author:

Daisuke Hirata

Email:

hiratadaisuke47@gmail.com

\section{INTRODUCTION}

There are two types of error in tennis, an unforced-error (UE) and a forced-error. The unforced-error is caused in the situation the player is able to select the shot and is in control of a point or a game. On the other hand, the forced-error is characterized as a miss caused by an opponent's superior play. It is important for coaches to assist players to reduce UE in tennis.

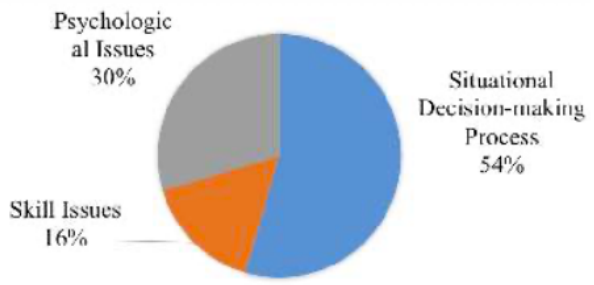

Figure 1. Results of the causes of UE from interviews by players.

Hirata et al. (2014) found several causes of UE in collegiate women tennis players: (a) situational decision-making processes, (b) skill issues, and (c) psychological issues (see Figure1).

There were differences in players' and coaches' perceptions of UE. It was considered that the cause of the UE was different when coaches thought the cause of player's UE. The cause of this as the UE is the variety, to know the cause of the UE of players and coaches are considered to be a valid information for coaching.

In the present study, several items representing the different elements of UE as identified in previous research (Hirata et al.,
2017; Shibahara, Tamaki, Hirata, Sonobe, Morii, \& Saijo, 2015) study were developed. Subsequently, the factor structure of a measure of UE was examined to establish validity of the tool using data from women's collegiate tennis in Japan.

\begin{tabular}{|c|c|c|c|c|}
\hline \multicolumn{5}{|c|}{ Playor } \\
\hline Skill evel & Number & Apeiyary & Fxpericenes in Tevirs tycaly & Couss Resut \\
\hline HS Plteger: & 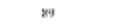 & $27.12 \pm 1.18$ & $12.28 \pm 237$ & 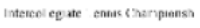 \\
\hline LS Players & 194 & $19.64+1.21$ & $10.4 n+331$ & Stose Temses Tourtanasat \\
\hline Tatal & 239 & $19.80 \pm 1.22$ & $11.88 \pm 216$ & \\
\hline \multicolumn{5}{|c|}{ Coaches } \\
\hline Sk:A Lowel & 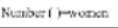 & Agetyur) & 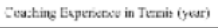 & Cetates Resuli of player \\
\hline Caucherof III Meysm & 39 & $45.31+1.57$ & 19.244581 & Intarsolligite level \\
\hline Ceaskess or LS rigyers & $38+4$ & 24.1212 .08 & 11.581955 & Stan Lered \\
\hline Iatal & $7(1)$. & $4214=1.651$ & & \\
\hline
\end{tabular}

Table 1. Groups details of players and coaches.

METHOD

The participants included 283 of collegiate women tennis players who belonged to a university tennis team and 77 of coaches who coached women tennis players in Japan (see Table 1 for demographic details the study participants). The criteria adopted to peer up players into High skilled (HS) and low skilled (LS) was based in their participation in Japan intercollegiate tennis championship or state tennis tournament, recognizing that the access of intercollegiate tennis championship is reserved for the winners of state tennis tournament. Coaches were also organized depending on the Championship played by their athletes. Ethical approval for this study was granted by Senshu University institute of sport ethics committee.

Table 1. Groups details of players and coaches. 
Based on previous research (Hirata e al., in press; Shibahara et al., 2015), 47 items were developed representing four factors (Distraction, Delay, Hesitation, and Anxiety). Sample items from the Distraction factor were: "I played sloppy" and "I was careless". "I was too confident with my shot" and "I was uncertain with my shot selection" were sample items of the Hesitation factor. Sample items from the third factor (Delay in the ready) included: "I was slow to regain possession" and "My timing was late with my stroke". The fourth factor (Anxiety) included the following sample items: "I was unconfident with my shot" and "I was anxious to play".

In the measure, players responded to the following stem: Player answered to remember the cause of UE in singles game and coaches responded to the following stem: Coach answer about UE of player coached by coach.

For each item, players and coaches were asked to rate Likert scale 1-5 with 1 representing "not at all" and 5 representing "always".

The analysis of items was analysed using exploratory factor analysis (EFA) was conducted. After this initial EFA, a Confirmatory Factor Analysis (CFA) was conducted to examine the factor structure of the measure using Amos 23.0. A comparison of players' and coaches' scores were analysed by a one-way ANOVA using SPSS 23.0.

RESULTS

The results of the EFA identified four factors contributing to

\begin{tabular}{|c|c|c|c|c|}
\hline (see & Table & & & \\
\hline Items & F1 & $\mathrm{H} 2$ & $\mathrm{H}_{3}$ & 54 \\
\hline \multicolumn{5}{|l|}{ F1 : Distraction $(\alpha=.755)$} \\
\hline A1 I played sioppy & .744 & -123 & .094 & .036 \\
\hline A2 I was careless. & .678 & .600 & .088 & .656 \\
\hline A3 I played with not encugh thought. & .652 & -.098 & 201 & .004 \\
\hline MI afforded tor much the time before making a hit. & .618 & .083 & .043 & $-.21 \times$ \\
\hline \multicolumn{5}{|l|}{ F2 : Hesilation $(\alpha=.797)$} \\
\hline B1 1 was to 0 confident with my shot. & .160 & .736 & 020 & .603 \\
\hline B2 I was uncertain with my shot solection. & .056 & .711 & 136 & .065 \\
\hline B3 I heritaled. & .091 & .682 & .197 & .205 \\
\hline B4 1 made a wreng decision. & .180 & .652 & .074 & .680 \\
\hline \multicolumn{5}{|l|}{ F3: Delay in the ready $\{\alpha=.766)$} \\
\hline Cl I was slow to regain possession. & .077 & -.096 & .814 & .034 \\
\hline C2 My timing was late with nyy stroke. & .010 & .039 & .691 & .092 \\
\hline C31 was uncoordinaled to make my shot. & ני & .017 & .585 & -.04 \\
\hline C4 I wasn'l prepared befure hilling (re-luat the limb). & .067 & .013 & .583 & .101 \\
\hline \multicolumn{5}{|l|}{ Fi : Anxiefy $(a=.748)$} \\
\hline DI I was uncen fident with my shol. & .165 & .606 & 068 & .881 \\
\hline D2 I was anxives to play. & .026 & .699 & 000 & .710 \\
\hline D3 I was not aggressive ennugh. & 161 & -.069 & 024 & .561 \\
\hline D4 I was nerwous. & .040 & .130 & -.079 & .415 \\
\hline \multicolumn{5}{|l|}{ Factor correlation matrix } \\
\hline$\Gamma 1$ : Distraction & 1.000 & & & \\
\hline F7. Hesiration & 376 & 1000 & & \\
\hline F3: De ay in the reacy & .449 & .504 & 1.000 & \\
\hline F4 : Anxicty & 323 & .349 & 387 & 1.000 \\
\hline
\end{tabular}

Table 2. Results of Exploratory Factor analysis (EFA).

From the EFA, it was found that all four items for each of the four factors loaded appropriately onto their expected factor. Furthermore, the four factors did not show high inter-factor correlations, partially supporting construct validity. Therefore, a CFA was conducted on the same data set. In the CFA, the goodness of fit indices showed a satisfactory fit of the data to this model (GFI=.910, AGFI=.877, CFI=.901, RMSEA=.070). Therefore, there is partial support for the construct validity of this measure of UE in tennis. The one-way Factorial ANOVA showed there were no statistical differences between the mean scores for low versus HS players for any of the four factors of UE. (see Table 3). However, there were significant differences between mean scores for coaches of HS versus LS players on three factors: Distraction $(F(75)=2.26, p .<.05)$, Delay in the ready $(F(75)=2.71$, p.<.01), and Anxiety $(F(75)$ $=2.33$,

p.<.05).

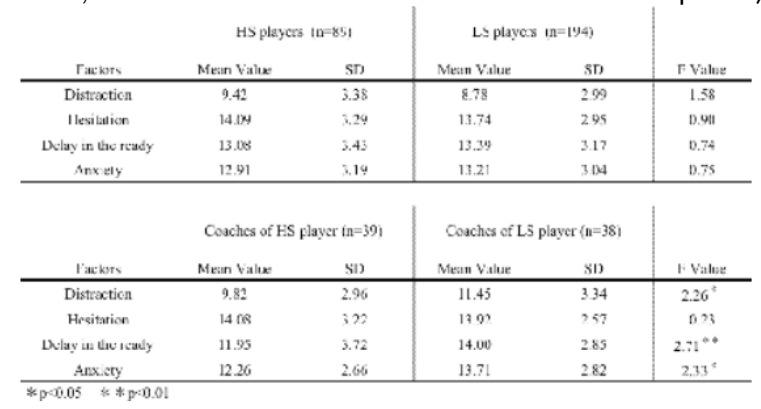

Table 3. To make a comparison between HS groups and LS groups.

An examination of the data between coaches of LS players and LS players only showed statistically different results for the Distraction factor $(F(230)=4.92, p .<.05)$ (see Figure 2).

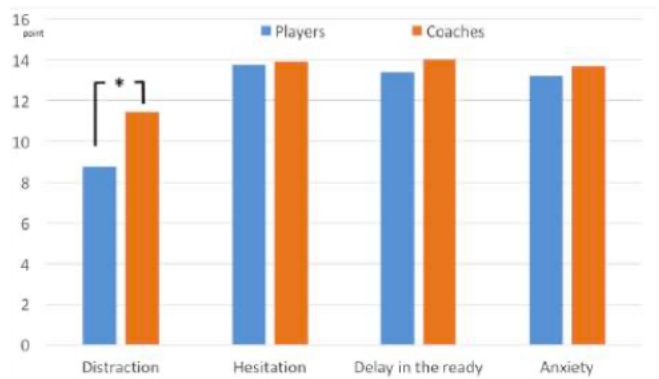

Figure 2. To make a comporson players and coaches of low skill group.

\section{DISCUSSION}

The causes of UE are considered an important issue in producing high performance in tennis. In present study, we found support for the four-factor structure of the UE measure: Distraction, Hesitation, Delay in the ready, and Anxiety. This initial examination of the psychometric structure of the UE measure has shown support for its structure, partially supporting the construct validity of UE. However, further examination of this measure is necessary to provide sufficient evidence of its reliability and validity as measure of UE.

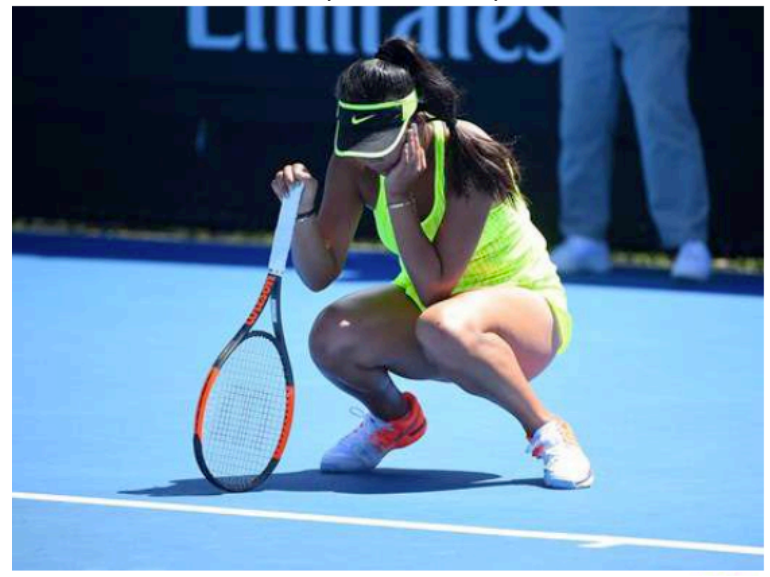


This measure is useful for researchers and coaches because it is important for coaching that coaches identify the causes of such errors. Mainly for LS players that struggle to attribute distraction as a reason for unforced-errors. Due to the simplicity of tactics and strategies in collegiate women tennis (Hirata et al., 2005) provide more space and opportunity for distractions. The role of coaches in such contexts must recognize the

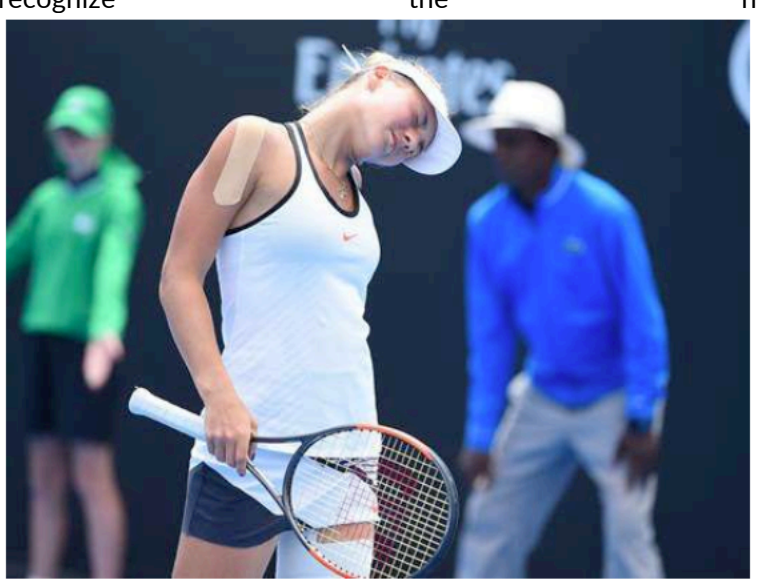

eed to emphasize the importance to remain focus.

Authors: Daisuke Hirata, Shuhei Sato, Kiso Murakami, Kentaro Shibahara, Daiji Morii, Daisuke Mitsuhashi, Junichi Sato, Msayuki Sato, Masamitsu Ito, Osamitsu Saijo.

\section{REFERENCES}

Conroy, D. E., \& Elliot, A. J. (2004). Fear of failure and achievement goals in sport: addressing the issue of the chicken and the egg. Anxiety, stress and coping, 17(3),

271285.https://doi.org/10.1080/1061580042000191 642

Davids, K. W., Button, C., \& Bennett, S. J. (2008). Dynamics of skill acquisition: A constraints-led approach: Human Kinetics.

Dekkers, H., \& Reardon, J. (2010). A guide to a new mentality: Mindset in a nutshell. ITF Coaching and sport science review, 18(52), 19-20.

Linnenbrink, E. A., \& Pintrich, P. R. (2002). Achievement goal theory and affect: An asymmetrical bidirectional model. Educational Psychologist, 37(2), 6978.https://doi.org/10.1207/S15326985EP3702_2

Mamassis, G., \& Doganis, G. (2010). The Effects of a Mental Training Program on Juniors Pre-Competitive Anxiety, Self-Confidence, and Tennis Performance. Journal of applied sport psychology, 16(2), 118137.https://doi.org/10.1080/1041320049043790 3

Pekrun, R. (2006). The control-value theory of achievement emotions: Assumptions, corollaries, and implications for educational research and practice. Educational psychology review, 18(4), 315341.https://doi.org/10.1007/s10648-006-9029-9

Pekrun, R., Elliot, A. J., \& Maier, M. A. (2006). Achievement goals and discrete achievement emotions: A theoretical model and prospective test. Journal of educational Psychology, 98(3), 583.https://doi.org/10.1037/0022-0663.98.3.583

Pekrun, R., Hall, N. C., Goetz, T., \& Perry, R. P. (2014). Boredom and academic achievement: Testing a model of reciprocal causation. Journal of educational Psychology, 106(3), 696.https://doi.org/10.1037/a0036006

Reynolds, K. (2013). Improving performance ITF Coaching \& sport science review, 21(60), 19-20.

Savoy, C., \& Beitel, C. (1997). The relative effect of a group and group/individualized program on state anxiety and state self- confidence. Journal of Sport Behavior, 20(3), 364-376.

Sanderson, J., Weathers, M., Snedaker, K., \& Gramlich, K. (2016). "I Was Able to Still Do My Job on the Field and Keep Playing" An Investigation of Female and Male Athletes' Experiences With (Not) Reporting Concussions. Communication \& Sport.https://doi.org/10.1177/216747951562345 5

Taylor, J. (1995). Aconceptual model for integrating athletes' needs and sport demands in the development of competitive mental preparation strategies. The Sport Psychologist, 9, 339357.https://doi.org/10.1123/tsp.9.3.339

Van Dinther, M., Dochy, F., \& Segers, M. (2011). Factors affecting students' self-efficacy in higher education. Educational Research Review, 6(2), 95108.https://doi.org/10.1016/j.edurev.2010.10.003

Zeidner, M. (1998). Test anxiety: The state of the art. New York: Plenum.

RECOMMENDED ITF TENNIS ACADEMY CONTENT (CLICK BELOW)

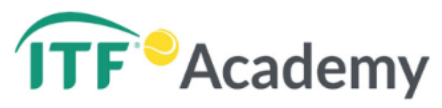

Copyright (c) Daisuke Hirata, Shuhei Sato, Kiso Murakami 2016

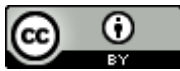

This text is under a Creative Commons BY 4.0 license

You are free to Share - copy and redistribute the material in any medium or format - and Adapt the content - remix, transform, and build upon the material for any purpose, even commercially under the following terms:

Attribution: You must give appropriate credit, provide a link to the license, and indicate if changes were made. You may do so in any reasonable manner, but not in any way that suggests the licensor endorses you or your use.

CC BY 4.0 license terms summary $\quad$ CC BY 4.0 license terms 